its instability, its short duration of action, and its requirement for carefully monitored infusion techniques.

For the present, then, we must accept that prostacyclin is indeed powerful and useful in extracorporeal shunts. How ironic that, despite its early claims to be a natural balancing substance in the thrombotic equation, the usefulness of prostacyclin has been most clearly proved in entirely man made settings where blood meets an artificial surface. In the common spontaneous vascular diseases we must recognise that not only is prostacyclin not yet of proved value but that it is unlikely to be so. The real hope here lies in the exploitation of this novel compound to generate a stable, orally active prostacyclin analogue which will have selective affinity for the platelet receptors and will have minimal effects on the heart and blood vessels. Like the inventor who answered his critics by saying "But what is the use of a newborn baby ?" we should be prepared to say of epoprostenol "Wait till it grows up and has children of its own-for what the world is waiting for is 'Son of Prostacyclin.' "'

Foundation Professor of Medicine,

J R A Mitcheli

Nottingham University,

University Hospital,

Nottingham NG7 2UH

1 Kurzrok R, Lieb CC. Biochemical studies of human semen; action of semen on the human uterus. Proc Soc Exp Biol Med 1930;28:268-72.

2 Bergström S. Chemistry of prostaglandin. Nordisk Medicin 1949;42 1465-6.

${ }^{3}$ Bergström S. Isolation, structure and action of the prostaglandins. In: Bergström S, Samuelsson B, eds. Prostaglandins. Proceedings of the 2nd Nobel symposium. Stockholm: Almqvist and Wiksell, 1967:21-30.

${ }^{4}$ Kloeze J. Influence of prostaglandins on platelet adhesiveness and platelet aggregation. In: Bergström S, Samuelsson B, eds. Prostaglandins. Proceedings of the 2nd Nobel symposium. Stockholm: Almqvist and Wiksell, 1967:241-52.

${ }^{5}$ Emmons PR, Hampton JR, Harrison MJG, Honour AJ, Mitchell JRA. Effect of prostaglandin $\mathrm{E}_{1}$ on platelet behaviour in vitro and in vivo. Br Med F 1967; ii :468-72.

${ }^{6}$ Elkeles RS, Hampton JR, Harrison MJG, Mitchell JRA. Prostaglandin $\mathrm{E}_{1}$ and human platelets. Lancet 1969;ii:111.

7 Vane JR. Inhibition of prostaglandin synthesis as a mechanism of action for aspirin-like drugs. Nature New Biology $1971 ; 231: 232-5$

${ }^{8}$ Hamberg M, Svensson J, Samuelsson B. Thromboxanes; a new group of biologically active compounds derived from prostaglandin endoperoxides. Proc Natl Acad Sci USA 1975;72:2994-8.

${ }^{9}$ Moncada S, Gryglewski R, Bunting S, Vane JR. An enzyme isolated from arteries transforms prostaglandin endoperoxides to an unstable substance that inhibits platelet aggregation. Nature 1976;263:663-5.

10 Whittle BJR, Moncada S. Pharmacology of prostacyclin and thromboxanes. Br Med Bull 1983;39:232-8.

11 Moncada S, Vane JR. Arachidonic acid metabolites and the interactions between platelets and blood-vessel walls. N Engl f Med 1979;300: 1142-7.

${ }^{12}$ Moncada S, Korbut R, Bunting S, Vane JR. Prostacyclin is a circulating hormone. Nature 1978;273:767-8

13 Anonymous. The prototype. Lancet $1982 ;$ ii :424.

14 Lewis PJ, Dollery CT. Clinical pharmacology and potential of prostacyclin. Br Med Bull 1983;39:281-4.

15 Sinzinger H, O'Grady J, Cromwell M, Hofer R. Epoprostenol (prostacyclin) decreases platelet deposition on vascular prosthetic grafts. Lancet 1983; : $: 1275-6$.

16 Szczeklik A, Nizankowski R, Skawinski S, Szczeklik J, Gluszko P, Gryglewski RJ. Successful treatment of advanced arteriosclerosis obliterans with prostacyclin. Lancet $1979 ; \mathrm{i}: 1111-4$

17 Mitchell JRA. Clinical aspects of the arachidonic acid-thromboxane pathway. Br Med Bull 1983;39:289-95.

${ }^{18}$ Gryglewski RJ, Nowak S, Kostkatrabka E, et al. Treatment of ischemic stroke with prostacyclin. Stroke 1983;14:197-202.

\section{Legislation and teenage sex}

To paraphrase Jane Austen, it is a truth universally acknow- $\bar{C}$ ledged that parliament should not make new laws when those $\bar{\Xi}$ most closely affected advise that the proposed legislation is D unwise and unworkable. Earlier this month the BMA called a \& press conference to leave the press and public in no doubt that 2 doctors do not want any change in the law governing the prescription of oral contraceptives for girls under the age of 16 . No one doubts the good intentions of most of those who want $\overline{0}$ to prohibit doctors from prescribing the pill in these circumstances without the consent of the girl's parents; but the campaigners have mostly been arguing from conviction rather $\stackrel{\mathbb{Q}}{\Omega}$ than experience. The attitude of doctors would have been very $\approx$ different if the call for legislation had come from the families $\vec{\circ}$ directly affected-namely, those in which 14 and 15 year olds have been prescribed the pill-or from doctors working with $\vec{\omega}$ teenagers. In practice the pressure has mostly come from adults shocked by reports of promiscuous sexual behaviour among adolescents but with little or no direct experience of the realities.

Doctors in family planning clinics or in general practice who are asked for advice on contraception by teenage girls have to make a pragmatic assessment. Almost always these girls have already formed a sexual relationship, often stable and overt. Most have no wish to keep their mothers in the dark; of those few who do ask for confidentiality, one third can be persuaded $\vec{V}$ at the first interview to tell their parents and another third $\mathbb{D}$

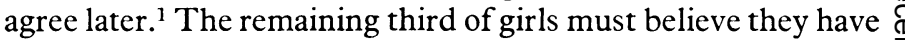
very strong reasons for rejecting the doctor's advice-for doctors do always make an attempt to bring the parent into the $\mathbb{\mathscr { \Phi }}$ picture. $^{2}$ Who will gain from a law insisting that in these $\vec{\bullet}$ circumstances the girl should be told that she may not be $\stackrel{\infty}{\omega}$ supplied with a contraceptive?

At the heart of the matter are the very different ways in which people think of teenage sexuality. Should pregnancy be seen as a punishment for illicit sex ? Is fear of pregnancy really an important deterrent ? If sexually active teenagers are denied $\stackrel{\mathbb{Q}}{\Omega}$ access to medical contraception are they more likely to stop $\overrightarrow{\hat{O}}$ having sex or to use some unreliable contraceptive technique $\exists$ that requires no prescription?

The BMA press conference spelt out the medical hazards of early sexual experience and of pregnancy; doctors working with schoolchildren are only too aware of the physical and psychological problems that may sometimes be associated with sexual activity in the early teens. But like it or not, doctors have to work in the real world. Over the years we have worked out a whole range of compromise solutions that seem to minimise damage to our patients; intending legislators should be extraordinarily certain that they have found a better answer.

Timmins N. All children's treatment threatened by pill challenge, doctors say. The Times 1983 Dec 2:3 (cols 1-3).

2 British Medical Association. Minors and contraception. The handbook of $\mathrm{C}$ medical ethics. London: British Medical Association, 1981:18. 